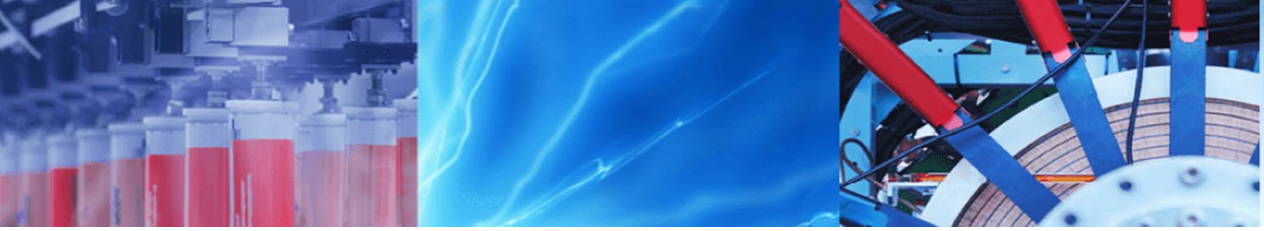

Research Article

\title{
Optimization of a load control system algorithm for electrically propelled ships using data mining
}

\author{
Jong-Hak Lee ${ }^{1} \cdot$ Hun-Seok Lee ${ }^{2} \cdot J_{i n}-S e o k \mathrm{Oh}^{1}$ (1)
}

Received: 11 March 2020 / Accepted: 30 December 2020 / Published online: 20 March 2021

(C) The Author(s) 2021 OPEN

\begin{abstract}
The international maritime organization is reinforcing regulations on ship emissions and carbon dioxide, such as sulfur and nitrogen oxides. To solve this, electric propulsion vessels can use a battery-controlled load control system (LCS) to satisfy emission regulations. In this study, load data measured for one year on a ship is analyzed using a self-organizing map (SOM). Based on the analysis results, the optimal power generation capacity and battery capacity are designed, and a LCS algorithm is built. Model the ship's power generation system using MATLAB Simulink to verify the algorithm and verify its effectiveness. The LCS algorithm proposed in this study has a $1.01 \%$ reduction in fuel consumption and a $10.97 \%$ battery charge compared to the existing LCS algorithm.
\end{abstract}

Keywords Electric propulsion system · Load control system · Energy consumption · Data mining · Ship simulation

\section{Introduction}

Crude oil used in ships contains sulfur and is discharged after combustion, the discharge causes respiratory symptoms, lung diseases and harms both land crops and marine organisms. Therefore, environmentally friendly shipbuilding technologies must be applied to prevent further environmental problems through energy saving. Environmental regulations on ship emissions such as sulfur oxides (SOx), nitrogen oxides (NOx) and carbon dioxide $\left(\mathrm{CO}_{2}\right)$ have also been recently strengthened [1]. Techniques for reducing the emission of such combustion materials include the installation of scrubbers and Selective Catalytic Reduction (SCR) or the use of low sulfur fuel oils [2-5]. In addition, there is a method of increasing the efficiency of the fuel-using device to produce high power or power through less fuel. The method of increasing the efficiency of the device has an advantage over the previous technology since no additional amount of money is lost [6]. In this study, we designed and simulated the capacity of generators and batteries used in electric propulsion vessels to increase the efficiency of equipment, and confirmed the effectiveness of the built algorithm.

Electric propulsion ships have a higher total power used in ships than mechanical propulsion ships due to the mounting of propulsion motors. In addition, the mechanical propulsion vessel transmits propulsion power generated by the main engine to the propeller through the shaft [7]. In contrast, an electric propulsion vessel produces electric power through a generator and drives a propulsion motor through a conversion process [8]. Therefore, the electric propulsion vessel has higher energy flexibility than the mechanical propulsion vessel. Using energy flexibility, it is possible to increase the efficiency of the generator by operating the LCS algorithm of the generator and the battery according to the variance of the load [9].

Although the study of the algorithm for the operation of the ship's power system considers the load currently being used, it does not consider the actual operational pattern. This method cannot prepare for peak load. In

$\triangle$ Jin-Seok Oh, ojs@kmou.ac.kr | ${ }^{1}$ Korea Maritime and Ocean University, Engineering, Busan 49112, Korea. ${ }^{2}$ Hanwha Systems, Naval R\&D Center, Gumi 39376, Korea. 
order to secure the stability of the peak load, an algorithm that includes the usage of the operating condition of peak load is essential. In this paper, we built a related equation to increase the ship's stability and efficiency and integrated it into an appropriate algorithm. In addition, the power consumption data collected demonstrates the operation status of the ship classified through SOM. This paper illustrates the load management system constructed according to the aforementioned data.

In addition, a method for designing optimal generator and battery capacity is performed. In general, the designs of the ship took into consideration the economic usage of equipment depending on operational conditions and capacity of its power system [10]. Therefore, stability of power supply is ensured by considering redundancy for capacity [11]. The proposed method is designed to simulate the data of the ship's operation and calculates the capacity of the power system through its simulation results. Therefore, it is possible to calculate the power system capacity optimized for the operation of the target vessel and the use pattern of auxiliary equipment. The established optimal generator and battery capacity is modeled using MATLAB Simulink, and the proposed LCS algorithm is simulated using scenarios based on actual ship operation data.

Chapter 2 describes the basic techniques for LCS. Chapter 3 analyzes the data using the specifications of the target vessel, the pre-processing of collected data, and the SOM. In addition, the necessary equations are introduced in the LCS. Chapter 4 describes the process for selecting the capacity of the generator and battery. Chapter 5 analyzes each device modeling and simulation results required for simulation.

\section{Power system using LCS}

\subsection{Electric propulsion system}

The loads of ships are continuously increasing due to the increasing size of ships and number of installed devices. Increasing the flexibility of energy utilization by integrating the propulsion and power systems via an electric propulsion system has the advantage of a generator design that can supply power to the entire system with a smaller capacity than separately designing the propulsion engine and generator motor [12]. The power systems of future ships must be able to instantly respond to changes in ship load and must provide reliable stability. Furthermore, from an economic standpoint, fuel efficiency should be increased, and the emissions of air pollutants should be minimized. Figure 1 shows the basic configuration of an electric propulsion system.

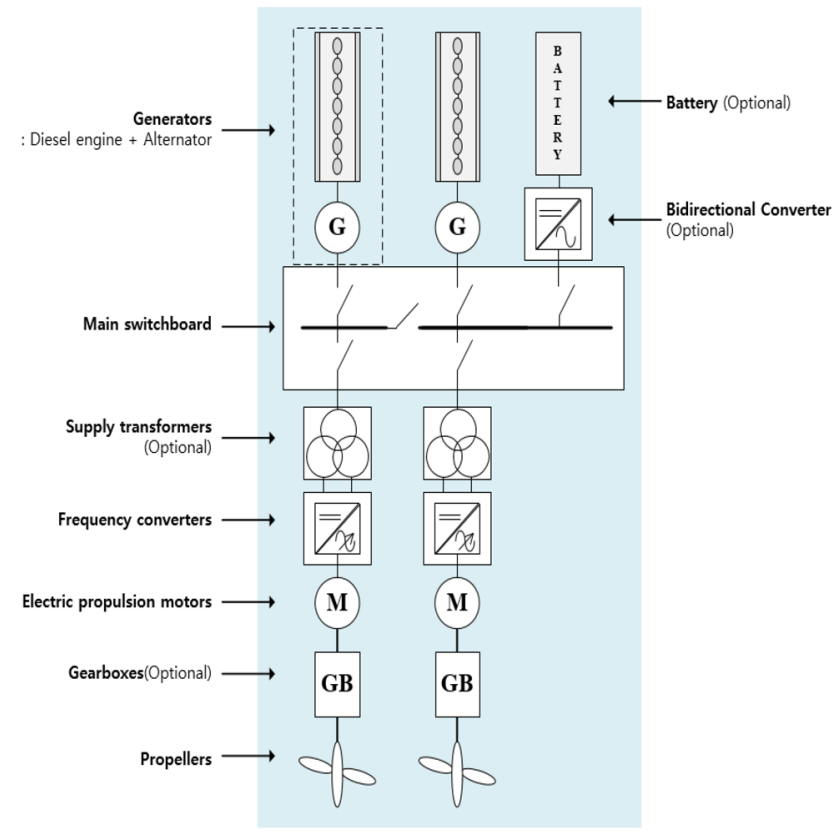

Fig. 1 Configuration of the electric propulsion system

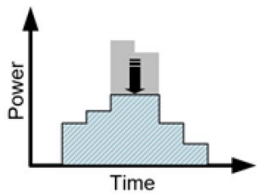

(a)

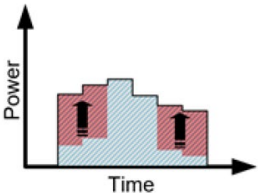

(b)

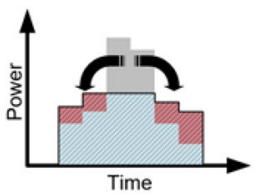

(c)
Fig. 2 Methods of managing energy demands: a peak shaving, b valley filling, and c load-sharing

\subsection{LCS}

The LCS aims at optimizing energy management between the generator and battery in a ship, and manages energy demand. Methods of managing energy demand include peak shaving, valley filling, and load-sharing, and management is performed strategically according to the system characteristics and environmental conditions. Figure 2 shows the methods of energy demand management [13].

\subsubsection{Peak shaving}

If a heavy load exceeding the generator margin occurs, an additional generator begins operating. Energy management using peak shaving does not operate an additional generator, and negligible loads that exceed the generator load ratio are temporarily blocked to prevent the operation of an additional generator. 


\subsubsection{Valley filling}

When a generator is operated under a low load, the power generation relative to the amount of fuel decreases, resulting in the reduction of power efficiency. Energy management using valley filling enables the generator to operate at a high efficiency by strategically increasing the load; this includes battery charging and load operation schedule management.

\subsubsection{Load-sharing}

Energy management using load-sharing combines peak shaving and valley filling. It reduces the peak load by operating an energy storage system and allows the generator load to operate in the optimum generation efficiency window.

In general, the battery operation algorithms referenced in the proposal did not consider two things: (1) power consumption pattern according to the operation mode of the ship, (2) extra power required according to the operation mode [14]. Figure 3 shows the power operation pattern of a typical electric propulsion container of a ship according to the ship's operating mode. The entry/departure shows higher power change compared to its anchoring and navigating states. The flexibility of energy cannot be accurately measured. This will soon lead to poor stability of power supply.

Each system of the ship is operated in a systematic way. In particular, the load fluctuates through the operation and suspension of each device, and there is a high fluctuation during its entry/departure. In shipyards, the load is called intermittent load, and the operating time of intermittent load as a diversity factor (\%) is measured in percentages. The required extra power must secure the extra power of the power source that the intermittent load can operate. If the spare power is taken into account, chattering may occur in the power generation's operation algorithm.

\section{Optimization via load analysis}

\subsection{Data collection}

\subsubsection{Overview}

The target ship for data collection was a 6,800 TEU container ship propelled with one diesel engine (69 MW MANB\&W; MAN Diesel SE, Germany) and consisting of four $3000 \mathrm{~kW}$ generators. The specifications of the target ship are summarized in Table 1. To analyze the ship load, the generator power data (e.g., output and load ratio), and the data, including engine output and speed, were collected for 411 days from November of 2014 to December of 2015 on a data collection cycle of $10 \mathrm{~min}$ (Table 2).

\subsubsection{Data preprocessing}

Electric and the mechanical propulsion systems have different power transmission efficiencies according to their system configurations. For the same output, an electric propulsion system undergoes more transformation processes than a mechanical system. Hence, the transformation efficiency is lower than that of the mechanical

\section{Pattern of Electrically Propelled Ships Power Consumption (kW)}

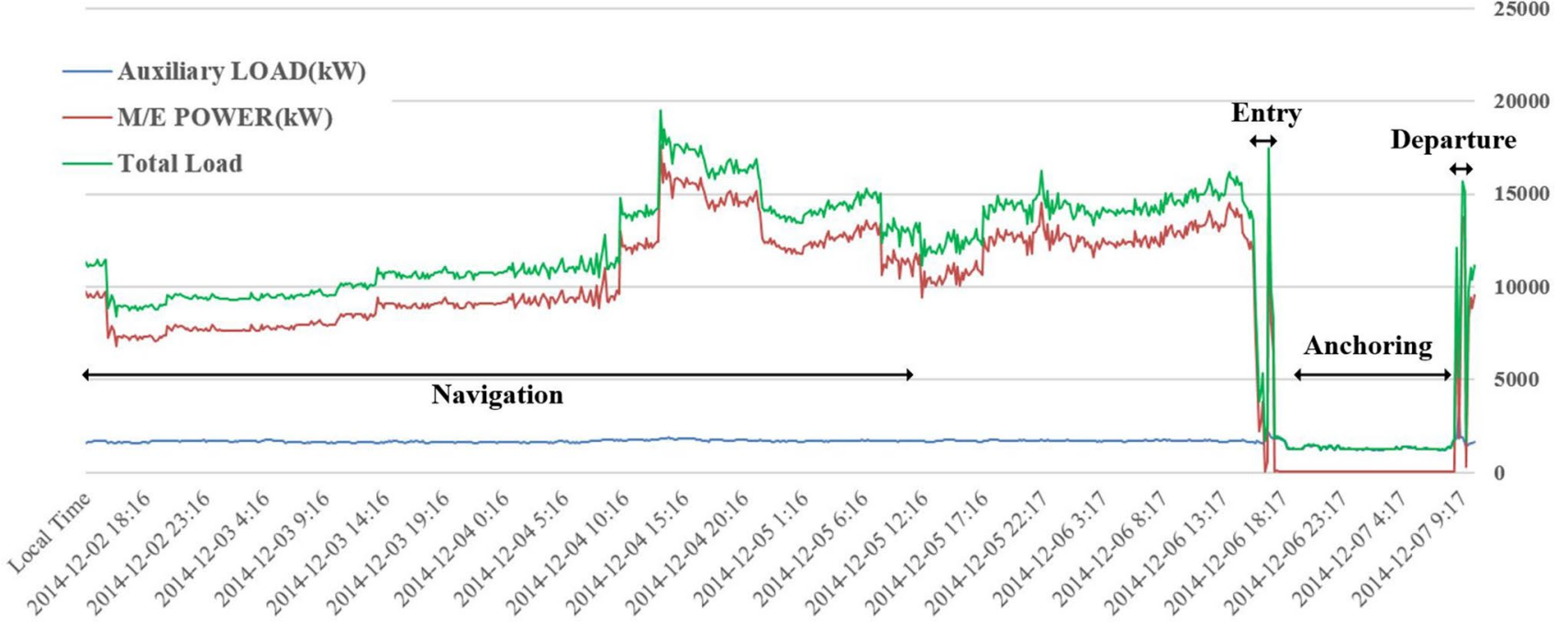

Fig. 3 Pattern of electrically propelled ships power consumption 
Table 1 Target ship specifications

\begin{tabular}{ll}
\hline Ship parameter & Specification \\
\hline Vessel type & Container \\
Length & $299 \mathrm{~m}$ \\
Width & $40 \mathrm{~m}$ \\
Draft & $13.5 \mathrm{~m}$ \\
Power of main engine & $68,520 \mathrm{~kW}$ \\
Power of generator & $3000 \mathrm{~kW}$ \\
& $\times 4$ \\
Velocity & $25 \mathrm{knot}$ \\
TEU $/$ Refrigerated containers & $6732 / 550$ \\
\hline
\end{tabular}

TEU twenty-foot equivalent unit

Table 2 Data acquisition list

\begin{tabular}{|c|c|c|}
\hline No & Data & Unit \\
\hline 1 & Time & MM-DD-TT \\
\hline 2 & No. 1 Gen'load & kW \\
\hline 3 & No. 1 Gen'start/stop & Boolean \\
\hline 4 & No. 2 Gen'load & $\mathrm{kW}$ \\
\hline 5 & No. 2 Gen'start/stop & Boolean \\
\hline 6 & No. 3 Gen'load & $\mathrm{kW}$ \\
\hline 7 & No. 3 Gen'start/stop & Boolean \\
\hline 8 & No. 4 Gen'load & $\mathrm{kW}$ \\
\hline 9 & No. 4 Gen'start/stop & Boolean \\
\hline 10 & Main engine start/stop & Boolean \\
\hline 11 & Ship speed & knot \\
\hline 12 & Main engine torque & $\mathrm{kg}_{\mathrm{f}} \cdot \mathrm{m}$ \\
\hline
\end{tabular}

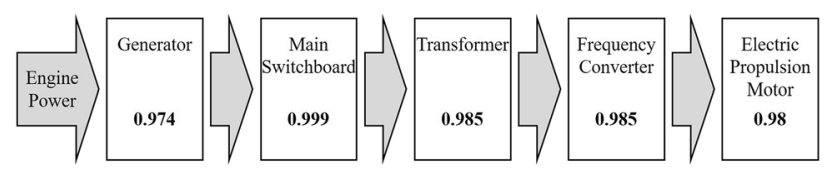

Fig. 4 Energy conversion efficiency of electric propulsion system

propulsion system. The target ship from which data were collected was transformed into a power system for use in this study. Figure 4 shows the transformation efficiency of the power system in the electric propulsion system $[15,16]$.

An axis efficiency of 0.97 was applied to engine use, and for the efficiency of using an electric propulsion motor, 0.89 was applied, considering the generator efficiency, transformer efficiency, electric propulsion motor efficiency, and axis efficiency. Subtracting the efficiency of using the engine and applying the efficiency of using the electric propulsion motor, the propulsion mode may be expressed as:
$P_{e . p}=0.75 \times \eta_{c} \times P_{m . p}$

where $P_{e \cdot p}$ is the propulsion load (electric propulsion motor; $\mathrm{kW}, \eta_{c}$ is the dimensionless transformation efficiency (0.92), and $P_{m . p}$ is the engine propulsion load (hp).

\subsubsection{Operation mode through the SOM}

Data mining is a method of detecting statistical rules or patterns in data. Among the data mining techniques based on artificial neural networks are SOMs, neural networks, and expert systems. Cluster analysis can identify groupings by clustering multivariate data according to their characteristics. If the number of clusters is not determined or the similarity between the data is determined through clustering on the initial data whose characteristics are unknown, it can be used to understand the distribution and structure of the underlying data. Ship data changes depending upon the operating environment or the characteristics of the operator. Therefore, cluster analysis is an effective means of analyzing such data [17].

In this study, the relationships of data measured in ships were clustered and the significance of the relationship between collected power data and ship operation mode was determined. The results were then used in the selection of variables in the load control algorithm. In the proposed load control algorithm (Fig. 6), the ship operation mode and the relationship data using SOM was used as a basis of evaluating the ship operation mode (anchoring, entry/departure, navigation). To generate the SOM, an appropriate number of nodes for the number of data must be input. Here the number of grids was selected in accordance with the number of data points, and an asymmetric grid configuration was used according to the number of data points. The number of grids can be determined by the following equation [18]:

$M=5 \sqrt{N}$

where $M$ is the grid count cells and $N$ is the number of observed data points for the target ( $\mathrm{pc}$ ).

Based on the generated grids, SOMs were generated for a total of 55 voyages. The data used for clustering were from the auxiliary load, propulsion load, total load, auxiliary load ratio, propulsion load ratio, and speed. The characteristics of load for each voyage were derived through clustering and used for the load control algorithm. Figure 4 shows the SOM results for Voyage 1.

The distance between grids (Fig. $5 \mathrm{a}$ ) indicates that the distance between clusters increased as the color changed from yellow to red and black. Figure $5 b$ shows the number of data points located in the grids. Voyage 1 can be largely divided into three clusters. When this is compared with the 

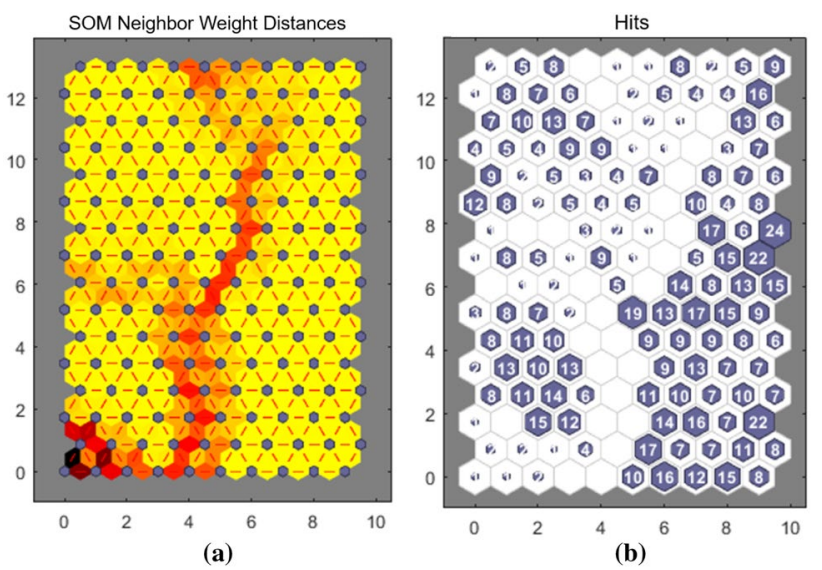

Fig. 5 SOM of Voyage 1: a neighbor weight distance and $\mathbf{b}$ hits

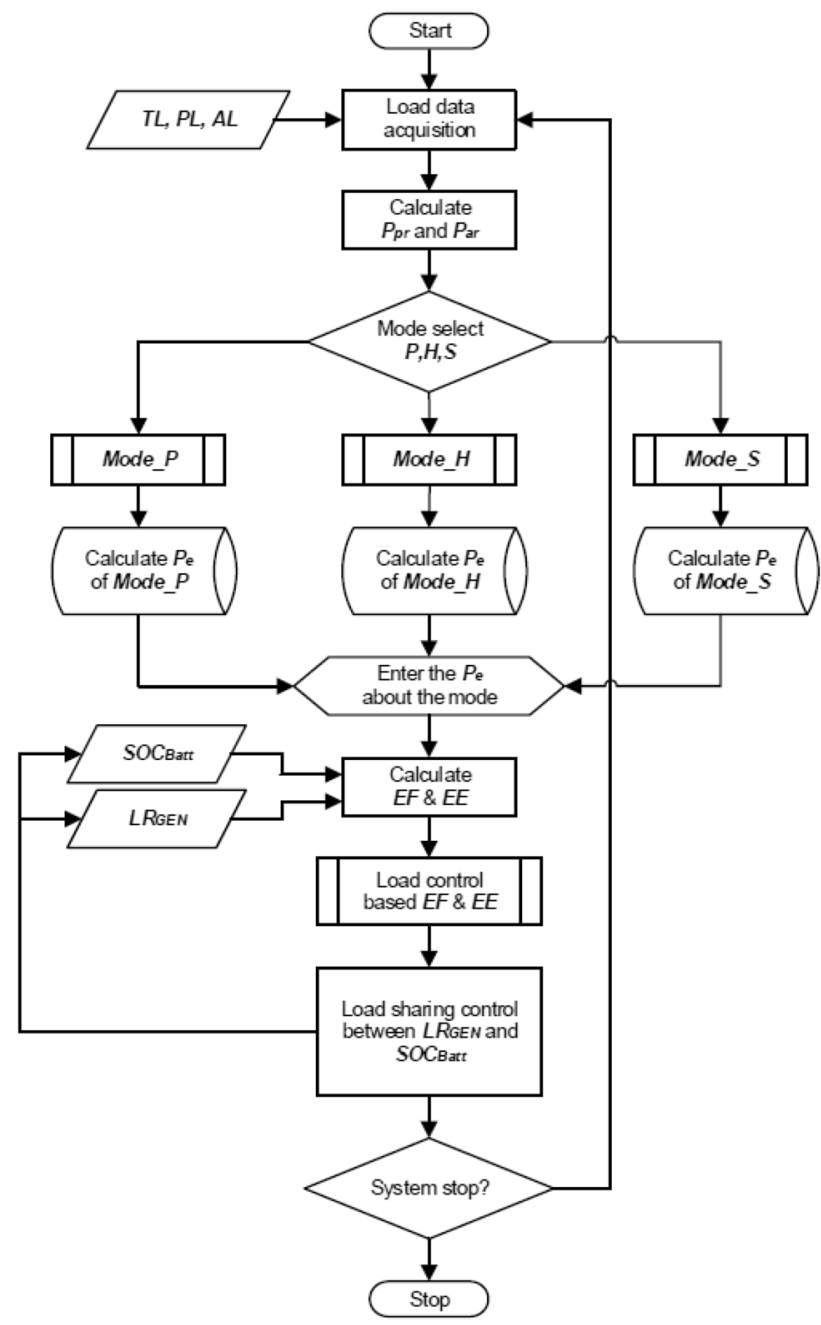

Fig. 6 Proposed LCS Algorithm operation mode of the ship, the top left, bottom left, and right side can be classified into anchoring, entry/departure, and navigation states, respectively.

\subsubsection{Characteristics of each operation mode}

From the SOM results for 55 voyages, the ship operation characteristics were analyzed by extracting the characteristics of grids with the largest number of data points for each cluster. In the navigation state, the propulsion load occupies a high percentage of the total load and a large change in load occurs. Therefore, a sufficient power margin must be secured to respond to load changes. This free power can be secured by giving a margin in the generator load ratio or through batteries. When the generator is operated in a high-efficiency window, the power margin can be insufficient; thus, a sufficient remaining battery capacity must be secured. The load control algorithm determines the load ratio and battery charge/discharge states between generators and batteries by considering the variable range of the propulsion load, the state-of-charge (SOC) of the battery, and the generator margin load ratio. In contrast, in the entry/ departure and anchoring state, the auxiliary load occupies a high percentage of the total load and the change in load is small. Thus, the power margin criteria of the generator and battery to respond to changes in load are lowered.

\subsection{Energy flexibility}

The energy coefficient was designed to determine the energy flexibility and energy efficiency of the load control algorithm. The energy flexibility is the degree to which the generator and battery are able to respond to changes in load. It is calculated on the basis of the secured power demand according to the mode by applying the characteristics of each mode. Energy efficiency indicates the degree of efficient operation of the generator.

\subsubsection{Calculation of energy flexibility}

The electric propulsion system can secure energy flexibility by load-sharing through the generator and battery and by lowering the load of the negligible load group depending upon the load state. In this study, the acquisition of energy flexibility through load-sharing between the generator and battery was researched. Thus, the energy flexibility in an electric propulsion system was defined as follows:

$E F=\frac{1}{P_{e}}\left(\sum_{k=0}^{n} P_{\text {gen.avail }}(k)+P_{\text {Batt }}\right)$

where $E F$ is the energy flexibility (dimensionless), $P_{e}$ is the required power margin $(\mathrm{kW}), n$ is the number of operating 
generators (units), $P_{\text {gen avail }}$ is the generator load margin $(\mathrm{kW})$, and $P_{\text {Batt }}$ is the available battery power. A large energy flexibility means that there is sufficient available energy relative to changes in load. When the energy flexibility is determined, the required power margin, $P_{e^{\prime}}$ is set and the condition that includes the third quartile of the possible load in the corresponding load is defined as $E F=1$. This means that a power margin has been secured to $P_{\text {average }}+3 \sigma$ of the expected peak load in the current load and it is possible to respond to load changes. Here, $\sigma$ denotes the standard deviation.

\subsubsection{Required power margin}

The required power margin is divided into a power margin for the propulsive load and a power margin for the auxiliary load. These two power margins have different values according to the operation mode. In the cases of navigation and entry/departure states, the power margin for the propulsive load is calculated based on the RPM of the propeller, and in the anchoring state, it is set to zero because there is no propulsion. Data analyses confirmed that the maximum change in Revolution Per Minute (RPM) in the navigation state was five on average. Therefore, in the navigation state, the power margin for the propulsive load, $P_{\text {e.s.p }}$ is expressed as follows:

$P_{\text {e.s.p }}=P_{p \cdot R P M+5}-P_{p \cdot R P M}$

where, $P_{p \cdot R P M+5}$ is the load when operating at $\geq 5$ RPM more than the present value, and $P_{p \cdot R P M}$ is the propulsion load when operating at the present RPM.

In the entry/departure state, the system must be always ready for maneuvering ( -0 to $42 \mathrm{rpm}$ ) due to the nature of the operation mode. Thus, it is calculated by the difference between the power used when operating at the maneuvering RPM and the current propulsion load. The following equation shows the power margin, $P_{e \cdot h \cdot p}$ of the propulsive load in the entry/departure state:

$P_{\text {e.s.p }}=P_{42}-P_{p \cdot R P M}$

where $P_{42}$ is the load when operating at 42 RPM (kW).

The power margin for the auxiliary load is calculated by the constant power margin for the maximum load used in the corresponding mode. The results show that it is $2300 \mathrm{~kW}$, $4000 \mathrm{~kW}$, and $1800 \mathrm{~kW}$ in the navigation state, entry/departure state, and anchoring states, respectively. Equation (6) expresses the power margin, $P_{e \cdot a}$ of auxiliary load:

$P_{e \cdot a}=P_{m \cdot a}-P_{p \cdot a}$

where $P_{m \cdot a}$ is the power margin (kW) required in each mode and $P_{p \cdot a}$ is the in-use auxiliary load (kW).

\subsubsection{Measurement of energy efficiency}

Energy efficiency is the degree of efficient operation of the power generation system and indicates how much the current operation load satisfies an optimum operation range based on the optimum load of the generator. The load control algorithm aims to enable operation with a high energy efficiency by adjusting the charge and discharge of battery. Here, energy efficiency is defined as follows:

$E E=\frac{1}{n} \sum_{k=0}^{g} \frac{P_{k}}{P_{o p}}$

where $E E$ is the energy efficiency coefficient (dimensionless), $P_{k}$ is the current load of the $k$ th generator $(\mathrm{kW}), P_{o p}$ is the optimum operation load of the generator $(\mathrm{kW})$, and $g$ is the number of generators.

\subsection{Proposed LCS algorithm}

Figure 6 shows the algorithm proposed in this paper. The LCS algorithm is divided into 5 stages: (1) mode setting, (2) required power margin determination, (3) EF, EE calculation, (4) load distribution, and (5) system status check. (1) The mode setting is based on the measured total load (AL, All of Load), propulsion load (PL, Propulsion Load), and auxiliary load (AL, Auxiliary Load). Decide. (2) In the stage of determining the required power margin, the required power margin is calculated according to the previously determined mode and Eq. (6). (3) During "the energy flexibility and energy efficiency calculation." stage, EF and EE are calculated through Eqs. (3) and (7). (4) In the load distribution stage, load distribution between the generator and the battery is performed based on energy flexibility and energy efficiency. (5) In the "system status check" stage, it checks the system status and exits or moves back to stage 1 .

\section{Calculation of generator capacity}

The propulsion load transmitted as a mechanical power was changed into a propulsion load transmitted as electric power, and the load operation characteristics of the target ship were analyzed for each operation mode. Based on the analytical results, the generator capacity was calculated for a virtual ship. The generator capacity design satisfied the following conditions:

1. It was based on four generators; 
2. One generator was redundant (i.e., it must be possible to operate the system to the maximum load with three generators);

3. The most frequent load was set at $80 \%$ of the generator capacity so that the generator could be operated frequently in the optimum efficiency window;

4. The generator capacity was designed as one type (same capacity for four units) or two types (same capacity for 2 units).

\subsection{Calculating the minimum capacity required for power generation through the maximum load}

The maximum load was determined by the highest total load that combined the propulsive and auxiliary loads. The maximum load was found by calculating the total load over time with the propulsive load converted into a power load and the power load in the existing mechanical propulsion system was used as an auxiliary load as follows:

$P_{\text {total.peak }}=\max \left(P_{e l, i j}+P_{p, i j}\right)$

where $P_{\text {total.peak }}$ is the maximum load $(\mathrm{kW}), P_{e l, i j}$ is the $i$ th auxiliary load of the $j$ th voyage $(\mathrm{kW})$, and $P_{p, i j}$ is the $i$ th propulsion load of the $j$ th voyage $(\mathrm{kW})$. From the collected load data, it was calculated as $P_{\text {total.peak }}=20,135 \mathrm{~kW}$.

\subsection{Selection of generator operational combinations}

The generator capacity was designed to maximize efficiency by operating the most frequent load at the optimum load. Four of the most frequent loads from the load data were selected, which were $1300 \mathrm{~kW}\left(P_{1}\right), 3400 \mathrm{~kW}$ $\left(P_{2}\right), 7800 \mathrm{~kW}\left(P_{3}\right)$, and $10,100 \mathrm{~kW}\left(P_{4}\right)$. Conditions were set to derive an operational combination of generators to consider safety and efficiency. Table 3 shows the combinations of generators: that (1) satisfied the minimum capacity required for power generation when three generators are operated, and.

(2) the generator must be operated at an $80 \%$ load ratio in the most frequent load range. A total of six

Table 3 Reference cases of generator load operational conditions

\begin{tabular}{lll}
\hline Case & Combination & $80 \%$ Load $(\mathrm{kW})$ \\
\hline 1 & $3 p_{3}$ & 29,250 \\
2 & $3 p_{4}$ & 37,875 \\
3 & $p_{1}+2 p_{4}$ & 24,025 \\
4 & $p_{2}+2 p_{4}$ & 24,450 \\
5 & $p_{3}+2 p_{4}$ & 33,050 \\
\hline
\end{tabular}

combinations of generator loads were prepared by adding a four $8000 \mathrm{~kW}$ generator case to the capacities designed by using the operational combinations in Table 3, and six combinations of generator capacities were selected (Table 4).

\subsection{Battery charge/discharge capacities using ship load data}

The required capacity that the battery must bear for the optimum load operation of the generator when using the load and distance based on the optimum load operation points and the charge/discharge tendency are derived using the following equations:

$B_{\text {diff }}=\left\{b_{p 1},+b_{p 2}, \cdots, b_{p n}\right\}$

$b_{p 1}=p_{1}-P_{t l}, b_{p 2}=p_{2}-P_{t \mid}, \cdots$,

$b_{p n}=p_{n}-P_{t l}$

$B_{\text {diff, } \max }=\max \left(B_{\text {diff }}\right)$,

$B_{\text {diff } \min }=\min \left(B_{\text {diff }}\right)$,

$B_{\text {diff, avg }}=\operatorname{average}\left(B_{\text {diff }}\right)$

where $B_{\text {diff }}$ is the power born by the battery over time $(\mathrm{kW})$, $P_{t /}$ is the load over time $(\mathrm{kW})$, and $B_{\text {diff }}$ can be determined using $p_{1}, p_{2}, \cdots, p_{n}$, which are the optimum generation load operation points, and $b_{p 1}, b_{p 2}, b_{p 3}, b_{p 4}$, which are differences in the load, $P_{t \mid}$, over time.

\subsection{Evaluation of generator-battery capacity for each generator combination}

To verify the center and scatter of the data by calculating the mean, maximum, and minimum of the required

Table 4 Selected combinations of generator capacities

\begin{tabular}{lll}
\hline Case & Combination & Total load $(\mathrm{kW})$ \\
\hline 1 & $P_{\min }$ & 33,500 \\
& & $(26,800)$ \\
2 & $4 P_{3}$ & 39,000 \\
& $(31,200)$ \\
3 & $4 P_{4}$ & 50,500 \\
& & $(40,400)$ \\
4 & $2 P_{1}+2 P_{4}$ & 30,750 \\
& & $(24,600)$ \\
5 & $2 P_{2}+2 P_{4}$ & 36,000 \\
& & $(28,800)$ \\
6 & $2 P_{3}+2 P_{4}$ & 47,000 \\
& & $(37,600)$
\end{tabular}


Fig. 7 Battery capacity by different generator combinations (shown in Table 4) capacity from the battery design of each generator combination for every voyage, the battery capacity of each generator combination was visualized as box plots. Figure 7 shows the plots for the required battery capacity for each generator combination. A smaller box indicates a higher density of data, which means that the generator capacity design can be operated at the optimum load. The figure shows that the simulation results showed that in Case 5, the battery capacity required at the optimum operation load of the generator was small and the significance was also low. This indicates that when the generator combination of Case 5 is applied, the generation system can be operated with a high efficiency and the battery capacity can be designed to be small. By considering the mean value and safety factor from the result of Case 5, the battery capacity was calculated as follows:

$C_{\text {battery }}=k \cdot B_{\text {avg }}$

where $C_{\text {battery }}$ is the battery capacity of the virtual ship $(\mathrm{kWh}), k$ is the dimensionless safety factor (1.1), and $B_{\text {avg }}$
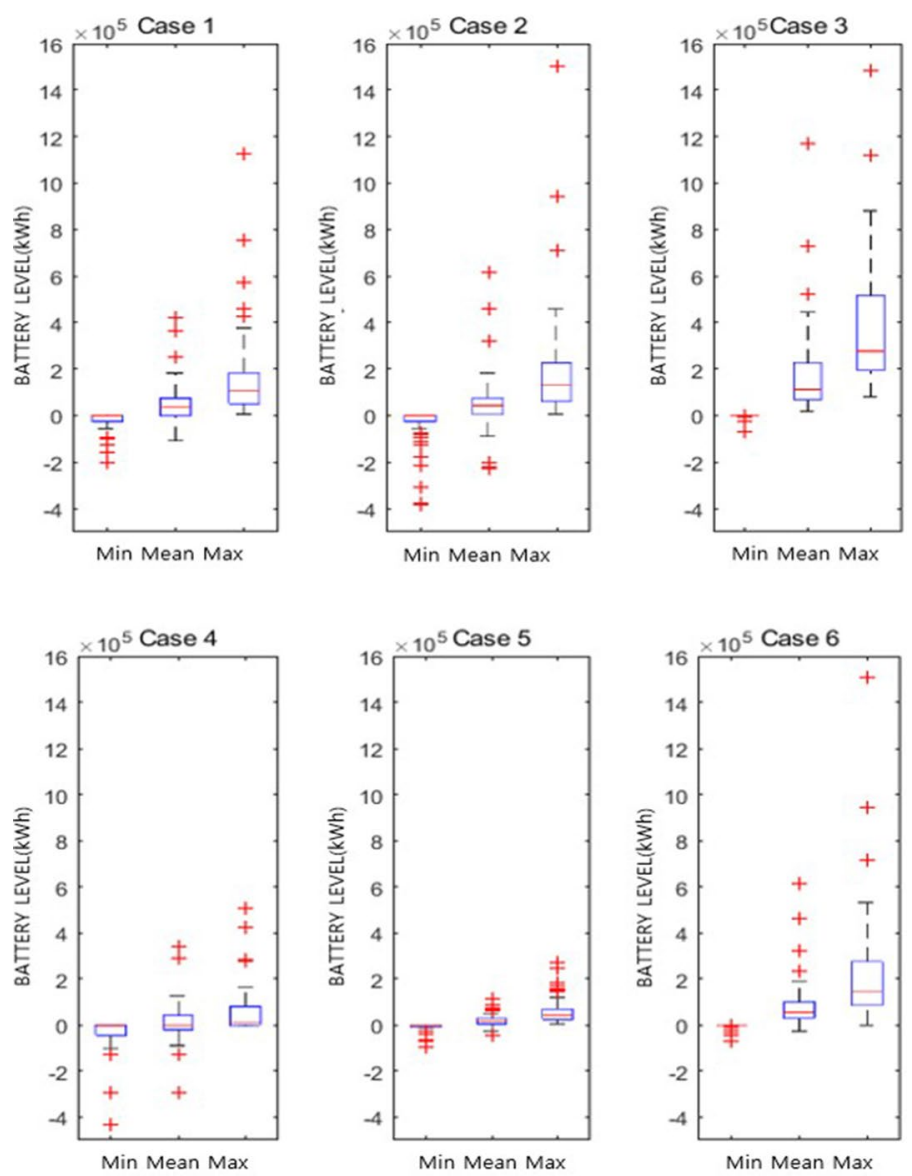

is the third quartile of the mean battery capacity required as a result of simulating each voyage ( $\mathrm{kWh}$ ).

\subsection{Selection of electric propulsion system capacity of the virtual ship}

In this study, the load control algorithm was verified using a virtual $6800-$ TEU container ship with an electric propulsion system consisting of generators and batteries. Table 5 summarizes the generator and battery capacities of the virtual ship. The generator capacity was selected based

Table 5 Generators and battery system capacities of a virtual container ship

\begin{tabular}{lc}
\hline Generator and battery & Capacity $(\mathrm{kW})$ \\
\hline No. 1 generator & 4250 \\
No. 2 generator & 4250 \\
No. 3 generator & 12,625 \\
No. 4 generator & 12,625 \\
Battery & 48,500 \\
\hline
\end{tabular}


on the load analyses and calculated in the unit of active power.

\section{Simulation}

Simulations were performed using MATLAB Simulink v. 9.2 (MathWorks, USA). The sub systems of the electric propulsion system consisted of power generation, power distribution, battery, load control, power control, and battery management system (BMS).

\subsection{Modeling}

In this study, modeling was divided into: (1) data input for loading system specifications and load scenarios from the work space of MATLAB, (2) the LCS, including the load-sharing algorithm between the generator and battery, (3) the power management system part that operates the generators according to the load distributed in accordance with the load control algorithm, (4) the power generation system that derives the fuel consumption rate by operating the generators according to the commands of the power management system, (5) the BMS that performs battery charge/discharge according to the load distributed by the LCS and prevents overcharge and over-discharge, (6) the battery, which calculates the battery capacity through charge and discharge according to the commands of the BMS, and (7) the distribution panel that combines the collected load scenario with the generator and battery data. Figure 8 shows the total simulation system.

The battery used in this study has a capacity of $48,500 \mathrm{~kW}$ according to the results presented in Chapter 4 . Meanwhile, the battery installed on the ship weighs about $11,000 \mathrm{~kg}$ per $1000 \mathrm{~kW}$ [19]. Thus, the total weight is about 533.5 TON. The battery proposed in this study is designed to replace ballast water. In addition, since the target vessel uses ballast water which is heavier than the battery, there is no change in the load itself based on the design.

\subsection{Results}

The load scenarios of 55 voyages were input into the model and the operations were verified for single control of the power control system and for integrated control of the load control and power control systems. Next, simulation results were visualized and analyzed for

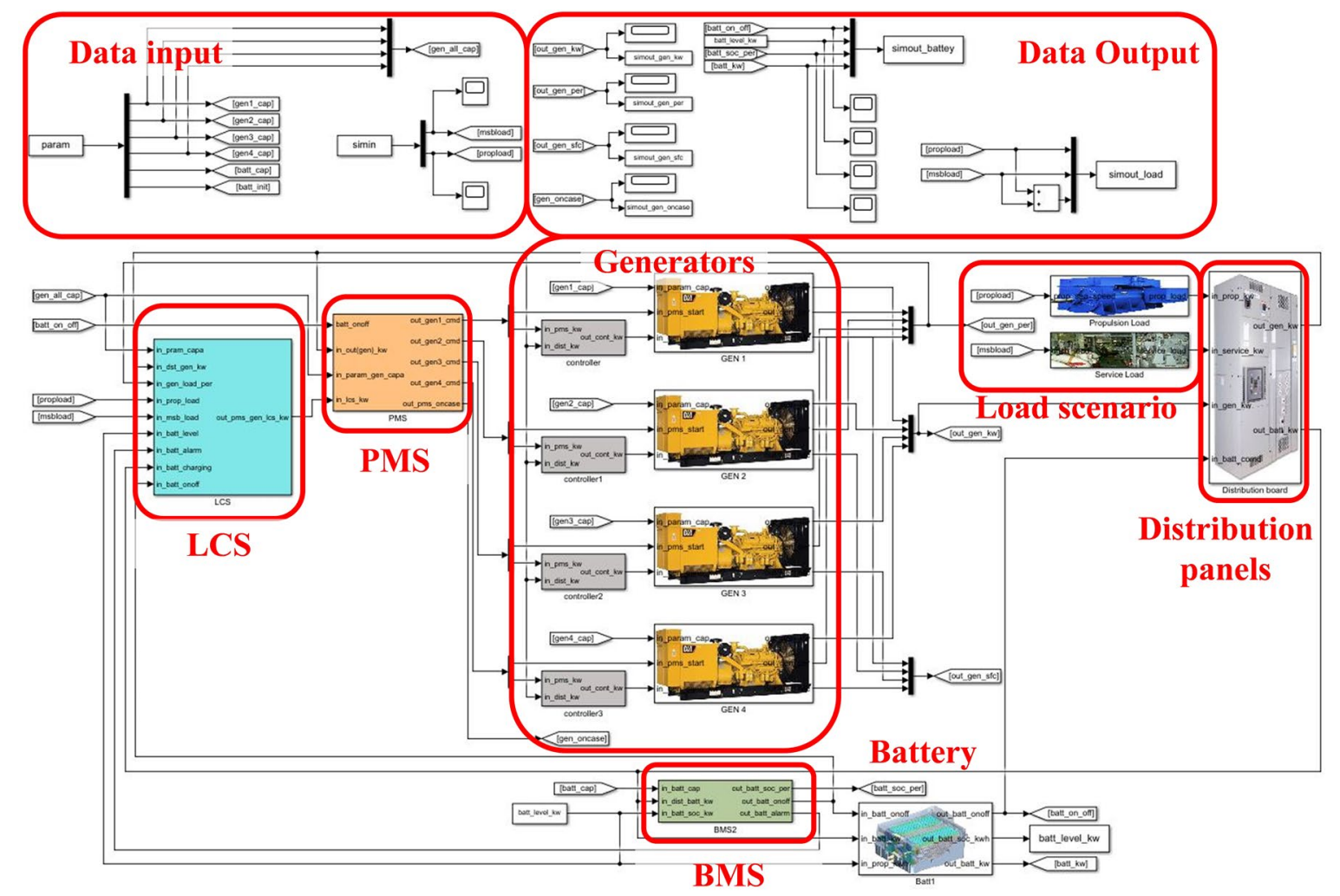

Fig. 8 Electric propulsion system simulator 


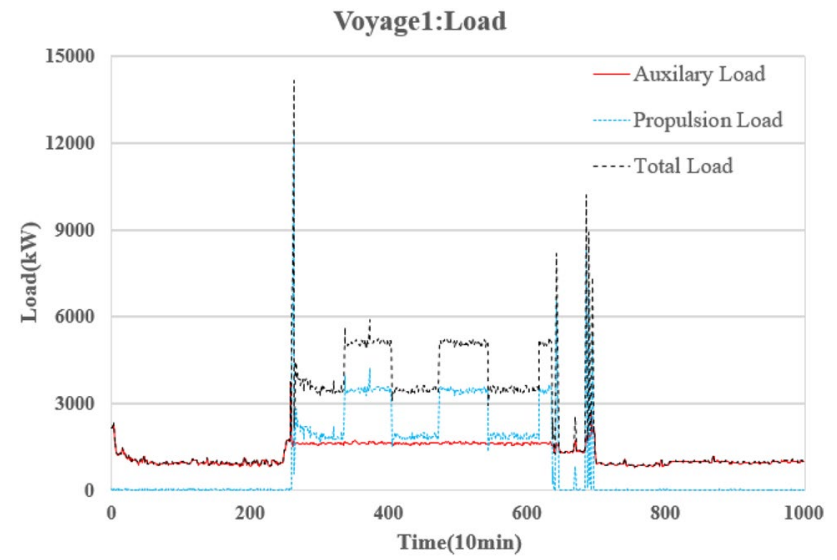

Fig. 9 Load scenario of Voyage 1

representative voyages among the 55 that allowed for comparison between the single control and integrated control systems.

\subsubsection{Load scenario}

The scenario based on the data measured by the actual ship and the propulsion load is calculated in reference to Fig. 3. The total load calculates the sum of the thrust load and the auxiliary load. Figure 9 shows the load scenario for Voyage 1 input into the LCS simulation. The time axis is divided into 10 min units. A large load occurred by the sum of a heavy load and a propulsive load in the entry/ departure at $2450 \mathrm{~min}$.

\subsubsection{Load-sharing among power sources}

Figure 10 shows the changes in load of the power source in the integrated control of the load control and power control systems. In the graph, a negative point in battery power indicates charging, and a positive number indicates discharging. When sufficient energy flexibility was provided, the generator load was adjusted to increase the energy efficiency. The load control algorithm increased the generator load while responding to the changes in load.

Figure 11a and $b$ show the LCS algorithm and Power Management System algorithm respectively. The algorithm of the generator load rate using the LCS is approximately $20-30 \%$ higher than that of the power management system in the anchoring section. In contrast for diesel engines, as the load increases, the consumption of fuel required to produce power decreases. This is expressed as specific fuel oil consumption (SFOC) [g/kWh] [20, 21].

Therefore, the LCS consumes less fuel than the power management system and produces the equal amount

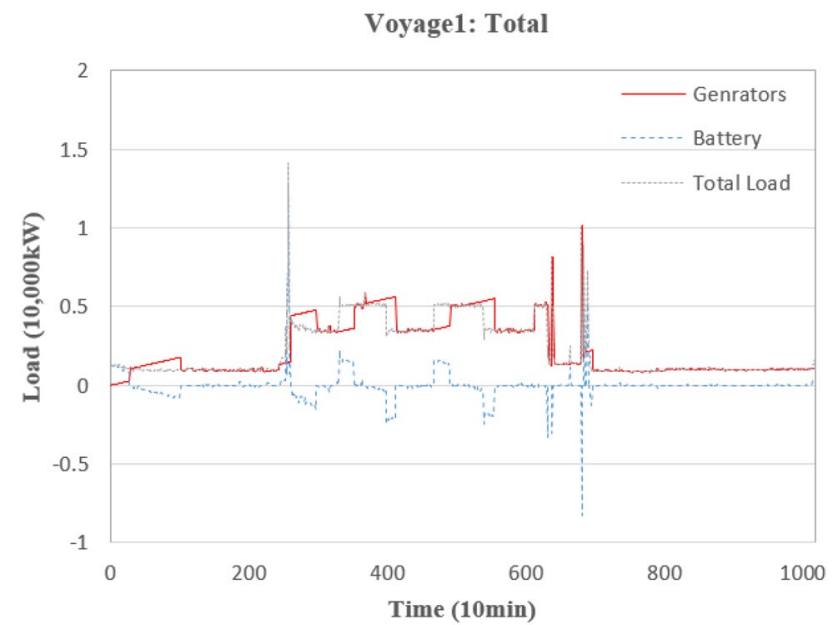

Fig. 10 Total load controlled by the LCS of Voyage 1

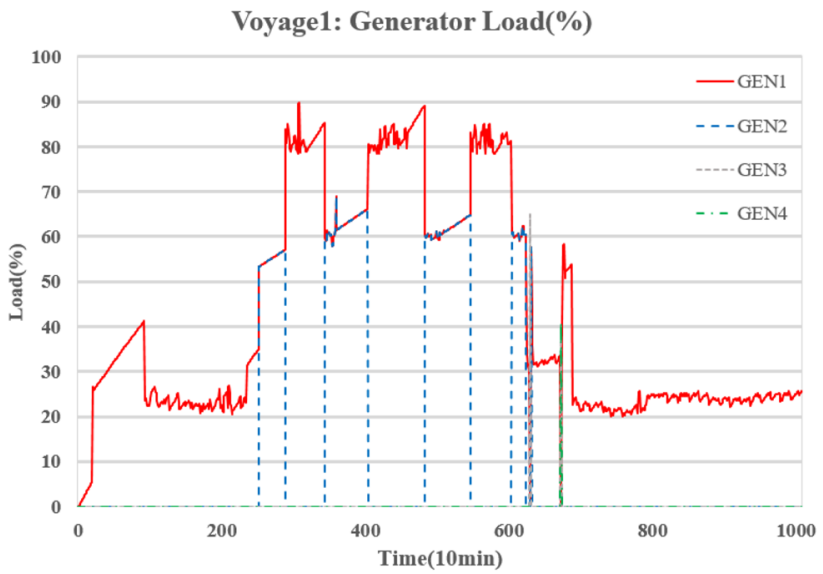

(a)

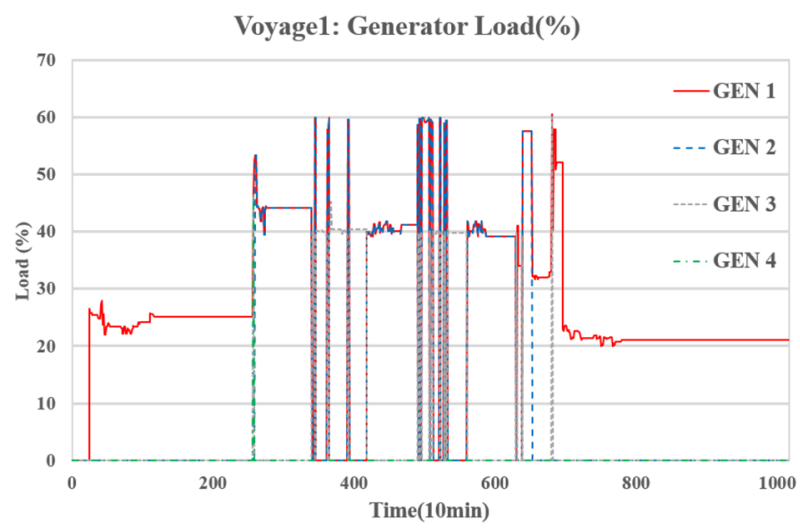

(b)

Fig. 11 Load ratio of Generator controlled by the LCS of Voyage 1

of power. In addition, due to the characteristics of diesel engines, the higher the load ratio, the lower the emission of Nox and Sox than the conventional fuel consumption 
$[22,23]$. Since the emission of the generator decreases as the load increases, the average load rate increases, thus the emission (Hydrocarbon ( $\mathrm{HC}$ ), Carbon monoxide (CO), Carbon dioxide $\left(\mathrm{CO}_{2}\right)$ and NOx) from driving the diesel engine decreases. As a result, as the consumption of fuel oil and the effect of emission reduction caused by the increase in the load ratio are added, a higher reduction rate can be expected.

\subsection{Analyses}

In the simulations, the fuel consumption of the LCS for each voyage was $98.98 \%$ relative to the power management system, and the battery charge was $10.97 \%$ relative to the power management system. Thus, in comparison with the single control of the power management system, the LCS reduced fuel consumption by $1.01 \%$ and increased the battery capacity by $10.97 \%$. In short, the LCS slightly improved the fuel reduction rate, and the battery charge rate was higher than the fuel reduction rate.

For some Voyages, the operation of the power management system resulted in lower fuel consumption. This is when the load control algorithm determined the energy flexibility of the system and charged the battery by increasing the load rate of the generator. Thus, the load-sharing function of the battery was not utilized. The advantages of quickly charging batteries are that they can reduce emissions by increasing the frequency of battery utilization when ships enter and leave the port. The main disadvantage of using less load-sharing functions, as shown in the simulation results, is that they will be improved.

\section{Discussion}

In this paper, we proposed the capacity design of battery and generator and LCS algorithm to verify the performance of energy efficiency algorithm through battery and generator of electric propulsion ship. In the power generation design, the combination of power generation sources was set so that the highest efficiency can be achieved in the range where the frequency of use of the load is high. In order to evaluate the set combination, the ship's operation scenario was evaluated in terms of voyages, and the highest efficiency was achieved with two $4250 \mathrm{~kW}$ generators and two $11,625 \mathrm{~kW}$ generators respectively and one $48,500 \mathrm{kWh}$ battery. In order to evaluate the efficiency of the proposed LCS algorithm, we calculated the fuel consumption according to the algorithm by using the operation scenario for each voyage of the ship and evaluated the fuel saving effect of the ship.
In some studies, battery usage is judged by the battery's SOC, current load, and generator capacity $[9,24]$. This has room for improvement in terms of efficiency as it only considers the stability of the power supply rather than energy efficiency. In this study, energy flexibility and energy efficiency are determined by reflecting the characteristics of operation, so efficiency and stability are ensured.

In the simulation using the generator and battery set in this study, the fuel saving effect of $1.0 \%$ compared to the existing algorithm was shown. In addition, it was confirmed that the generator is mainly operated at about $80 \%$ of the load factor. The fuel used by the ship depends on the combustion conditions and the amount of emissions varies. In general, the higher the load ratio of the generator, the lower the amount of discharged per unit power, so it is estimated that it will reduce the amount of emissions by more than $1 \%$ compared to power consumption.

\section{Conclusion}

The load control algorithm developed in this study consists of a mode setting through data collection, the required power margins for the mode, calculations of energy flexibility and efficiency, and load-sharing between the generator and battery based on the calculated energy coefficient. For the mode setting, the load data and speed of the ship were analyzed using SOMs, which allows the power margin of the load control algorithm to be set differently according to the load operational characteristics. The load control algorithm was designed to control the energy operation of the power generation system through the load ratio control of the generator and the charge/ discharge control of the battery based on the energy efficiency and energy flexibility. To verify the changes in energy reduction and efficiency when a load control algorithm is applied to a merchant ship, a virtual container ship with an electric propulsion system was designed based on an actual ship in operation. These results verify that the proposed algorithm is effective in terms of fuel reduction and battery charge rates. The LCS was built to optimize energy flexibility and energy efficiency. Although there are limits to such optimization, in the future, energy flexibility and energy efficiency will be further enhanced through machine learning.

Acknowledgements This research was supported by the Ministry of Education of the Republic of Korea and the National Research Foundation of Korea (NRF-2018R1D1A1B07049361) and Korea Institute of Marine Science and Technology promotion (PJT201192). 


\section{Compliance with ethical standards}

Conflict of interest The authors declare that there is no conflict of interest.

Open Access This article is licensed under a Creative Commons Attribution 4.0 International License, which permits use, sharing, adaptation, distribution and reproduction in any medium or format, as long as you give appropriate credit to the original author(s) and the source, provide a link to the Creative Commons licence, and indicate if changes were made. The images or other third party material in this article are included in the article's Creative Commons licence, unless indicated otherwise in a credit line to the material. If material is not included in the article's Creative Commons licence and your intended use is not permitted by statutory regulation or exceeds the permitted use, you will need to obtain permission directly from the copyright holder. To view a copy of this licence, visit http://creativecommons .org/licenses/by/4.0/.

\section{References}

1. International Maritime Organization (2019). Sulphur 2020 -cutting sulphur oxide emissions. http://www.imo.org/en/media centre/hottopics/pages/sulphur-2020.aspx

2. Endres $S$, Maes F, Hopkins F, Houghton K, Mårtensson EM, Oeffner J, Quack B, Singh P, Turner D (2018) A New perspective at the ship-air-sea-interface: the environmental impacts of exhaust gas scrubber discharge. Front Mar Sci 5:139. https://doi. org/10.3389/fmars.2018.00139

3. Panasiuk I, Turkina $L$ (2015) The evaluation of investments efficiency of SOx scrubber installation. Transp Res Part D Transp Environ 40:87-96. https://doi.org/10.1016/j.trd.2015.08.004

4. Kim HS, Kasipandi S, Kim J, Kang SH, Kim JH, Ryu JH, Bae JW (2020) Current catlyst techonolgy of selective catalytic reduction (SCR) for NOx removal in South Korea. Catalysts 10:52. https ://doi.org/10.3390/catal10010052

5. Achmann S, Hagen G, Hammerle M, Malkowsky I, Kiener C, Moos $R$ (2010) Sulfur removal from low-sulfur gasoline and diesel fuel by metal-organic frameworks. Chem Eng Technol 33(2):275-280

6. Kim K, Park K, Lee J, Chun K, Lee S (2018) Analysis of battery/ generator hybrid container ship for $\mathrm{CO} 2$ reduction. IEEE Access 6:14537-14543. https://doi.org/10.1109/ACCESS.2018.2814635

7. Benvenuto G, Campora U, Trucco A (2014) Comparison of ship plant layouts for power and propulsion systems with energy recovery. J Marine Eng Technol 13(3):3-15. https://doi. org/10.1080/20464177.2014.11658117

8. Khan MMS, Faruque MO (2016) Management of hybrid energy storage systems for mvdc power system of all electric ship. North Am Power Symp 2016:1-6. https://doi.org/10.1109/ NAPS.2016.7747993

9. Alfieri L, Mottola F, Pagano M (2019) An energy saving management strategy for battery-aided ship propulsion system. IEEE Milan PowerTech 2019:1-6. https://doi.org/10.1109/ PTC.2019.8810670
10. Chin H, Su C, Liao C (2016) Estimating power pump loads and sizing generators for ship electrical load analysis. IEEE Trans Ind Appl 52(6):4619-4627. https://doi.org/10.1109/TIA.2016.26006 53

11. Boveri A, Silvestro F, Gualeni P (2016) Ship electrical load analysis and power generation optimisation to reduce operational costs. 2016 international conference on electrical systems for aircraft, railway, ship propulsion and road vehicles \& international transportation electrification conference (ESARS-ITEC), 1-6, doi: https ://doi.org/10.1109/ESARS-ITEC.2016. 7841422

12. Lim JK, Jin HH, Kim TI, Lee UK, Kim JH (2011) Future ship and advent of its business model. Korea Marit Inst 4(3):1-186

13. Kouzelis K (2015) Load and flexibility models for distribution grid management. Dissertation, Aalborg University

14. Zhang C, Jia B (2019) Research on energy efficiency optimization strategy of electric propulsion ships with energy storage devices. Chin Automat Congr (CAC) 2019:4689-4694. https:// doi.org/10.1109/CAC48633.2019.8997039

15. MAN Engines (2019) Diesel-electric propulsion plants, a brief guideline how to engineer a diesel-electric propulsion system. https://marine.mandieselturbo.com/docs/librariesprovider6/ marine-broschures/diesel-electric-drives-guideline.pdf

16. Hodge CG, Mattick DJ (1997) The electric warship II. Trans. - inst. Mar Eng 109:138-144

17. Fayyad U, Piatetsky-Shapiro G, Smyth P (1996) From data mining to knowledge discovery in databases. Al Mag 17(3):37-54. https ://doi.org/10.1609/aimag.v17i3.1230

18. Ahn HJ, Shin JY, Jeong CS, Heo JH (2018) Assessing applicability of self-organizing map for regional rainfall frequency analysis in South Korea. J Korea Water Resour Assoc 51(5):383-393

19. Tummakuri V, Chelliah TR, Ramesh US (2020) Sizing of energy storage system for a battery operated short endurance marine vessel, 2020 IEEE international conference on power electronics, smart grid and renewable energy (PESGRE2020), 1-6. doi: https ://doi.org/10.1109/PESGRE45664.2020.9070268

20. Singh $H$ (2016) Study of emission characteristics and noise of dual fuel engine run on blends of diesel and producer gas from biomass materials. Dissertation, Thapar University

21. Alexandros Priftis (2015) Parametric design and multi-objective optimization of a 6,500 TEU container ship. Dissertation, National Technical University of Athens

22. Shirneshan $A$ (2013) HC, CO, CO2 and NOx emission evaluation of a diesel engine fueled with waste frying oil methyl ester. Procedia Soc Behav Sci 75(3):292-297

23. Tan YH, Abdullah MO, Nolasco-Hipolito C, Zauzi NSA, Abdulla GW (2017) Engine performance and emissions characteristics of a diesel engine fueled with diesel-biodiesel-bioethanol emulsions. Energy Convers Manag 132:54-64

24. Banaei MR, Alizadeh R (2016) Simulation-based modeling and power management of all-electric ships based on renewable energy generation using model predictive control strategy. IEEE Intell Transp Syst Mag 8(2):90-103. https://doi.org/10.1109/ MITS.2016.2533960

Publisher's Note Springer Nature remains neutral with regard to jurisdictional claims in published maps and institutional affiliations. 